Research Article

\title{
The Protective Effects of Melatonin on Aluminum-Induced Hepatotoxicity and Nephrotoxicity in Rats
}

\author{
Mohamed S. Othman $\mathbb{D}^{1,2}$ Mohamed A. Fareid, ${ }^{1,3}$ Reda S. Abdel Hameed,, \\ and Ahmed E. Abdel Moneim (iD) 5 \\ ${ }^{1}$ Basic Sciences Department, Preparatory Year, University of Ha'il, Ha'il, Saudi Arabia \\ ${ }^{2}$ Chemistry Dept., Faculty of Biotechnology, October University for Modern Science and Arts (MSA), Giza, Egypt \\ ${ }^{3}$ Botany and Microbiology Department, Faculty of Science, Al-Azhar University, Cairo, Egypt \\ ${ }^{4}$ Chemistry Department, Faculty of Science, Al-Azhar University, Cairo, Egypt \\ ${ }^{5}$ Department of Zoology and Entomology, Faculty of Science, Helwan University, Cairo 11795, Egypt
}

Correspondence should be addressed to Mohamed S. Othman; mo.abdelkarim@uoh.edu.sa and Ahmed E. Abdel Moneim; aest1977@hotmail.com

Received 30 July 2020; Revised 19 September 2020; Accepted 4 October 2020; Published 19 October 2020

Academic Editor: Hassan Obied

Copyright (C) 2020 Mohamed S. Othman et al. This is an open access article distributed under the Creative Commons Attribution License, which permits unrestricted use, distribution, and reproduction in any medium, provided the original work is properly cited.

\begin{abstract}
Aluminum ( $\mathrm{Al})$ is a ubiquitous element with known toxicity for both humans and animals. Herein, we aimed to investigate the potential role of melatonin (MEL) in hepatotoxicity and nephrotoxicity following aluminum chloride $\left(\mathrm{AlCl}_{3}\right)$ treatment in rats. Adult male rats were treated with $\mathrm{AlCl}_{3}\left(34 \mathrm{mg} / \mathrm{kg}\right.$ bwt) for eight weeks. Exposure to $\mathrm{AlCl}_{3}$ enhanced the serum activities of the liver transaminases (alanine aminotransferase and aspartate aminotransferase) and increased the level of bilirubin, in addition to the serum kidney function markers urea and creatinine. $\mathrm{AlCl}_{3}$ intoxication boosted oxidative stress, as evidenced by increases in the levels of lipid peroxidation (LPO) and nitric oxide (NO) along with simultaneous decreases in the levels of glutathione (GSH), various antioxidant enzymes, and Nrf2 mRNA expression. MEL (5 mg/kg bwt) treatment repressed LPO and NO levels, whereas it augmented GSH content. The activities of the antioxidant enzymes GPx, SOD, CAT, and GR were also restored concomitantly when MEL was administered before $\mathrm{AlCl}_{3}$. MEL also suppressed the apoptotic effect of $\mathrm{AlCl}_{3}$ by enhancing $\mathrm{Bcl}-2$ protein expression in the liver and kidney and decreasing the expression levels of proinflammatory cytokines. Histopathological findings in the liver and kidney tissues confirmed the beneficial effect of $\mathrm{MEL}$ against $\mathrm{AlCl}_{3}$ toxicity. These findings indicate that MEL prevents $\mathrm{AlCl}_{3}$ toxicity by enhancing the antioxidant defense system.
\end{abstract}

\section{Introduction}

Humans and animals interact daily with their environment and are exposed to a wide range of chemicals and heavy metals, which can bioaccumulate in the body and collect in tissues with low excretion [1]. The third most abundant metallic element in Earth's crust is aluminum (Al) [2]. Avoiding exposure to $\mathrm{Al}$ is almost impossible as it is used in various daily applications, such as water treatments, wood preservation, shampoos, vitamins, food additives, packaging materials, antiperspirants, toothpaste, medicines, or as fillers in plastics [3]. Commonly, $\mathrm{Al}$ reaches humans by breathing ambient air and intaking contaminated food and water [4].
Furthermore, particulate matters produced by cement factories and industrial wastewater contain a high amount of $\mathrm{Al}$, which leads to exposure to higher than the allowable levels of $\mathrm{Al}$ [5]. The average weekly intake of $\mathrm{Al}$ is estimated to be nearly 70-140 mg, and even with low gastrointestinal absorption capacity (less than 1\%), Al might concentrate over time in essential organs, such as the brain, liver, and kidney, with apparent neurotoxicity and cytotoxicity. Hence, $\mathrm{Al}$ is included in the priority list of dangerous materials authorized by the Agency for Toxic Substances and Disease Registry (ATSDR) [3].

Several reports have demonstrated that the in vivo and in vitro toxicities of $\mathrm{Al}$ negatively affect cellular structure 
and macromolecules, which lead to cytotoxicity, ROS generation, mitochondrial dysfunction, inflammation, cell death, genetic damage, and carcinogenicity [5]. Sun et al. [6] reported that excessive exposure to $\mathrm{Al}$ exerts toxic effects on the nervous, respiratory, reproductive, and immune systems, in addition to the liver and bone. Meanwhile, Lentini et al. [7] reported that much of the $\mathrm{Al}$ that accumulates in the human body comes from contaminated food and water, and a smaller amount enters through the skin. The majority of this $\mathrm{Al}$ is rapidly removed by the kidneys, which leads to nephrotoxicity and renal impairment. Additionally, Wang et al. [8] concluded that $\mathrm{Al}$ accumulation in the hepatic tissue causes hepatotoxicity, and Al-Kahtani et al. [9] recently found that Al-induced hepatotoxicity causes oxidative stress and apoptosis in rats.

Melatonin (MEL) is synthesized and secreted by the pineal gland. It regulates many biological functions, such as the circadian rhythm, sleep, reproduction, and immunity [10]. Many studies have indicated that MEL has several pharmacological effects, including antioxidant, anticancer, antiinflammatory, antiapoptotic, and immunomodulatory effects $[10,11]$. In particular, Al-Olayan et al. [2] concluded that MEL is a pleiotropic hormone that exerts efficient protection against oxidative/nitrosative injury by various mechanisms.

Since there is always a need for an outstanding therapeutic agent that could suppress the initiation and progression of hepatotoxicity and nephrotoxicity, the current investigation was designed to determine the potential effect of exogenous MEL in modulating $\mathrm{Al}$-induced toxicity and oxidative stress as well as its effect on nuclear factor erythroid 2-related factor 2 (Nrf2) gene expression in the liver and kidney tissues.

\section{Materials and Methods}

2.1. Chemicals. All the chemicals used in this study were of analytical grade and were purchased from Sigma-Aldrich Chemical Co. (St. Louis, MO, USA). Aluminum chloride $\left(\mathrm{AlCl}_{3}\right)$ anhydrous (CAS number 7446-70-0) was dissolved in $0.9 \%$ sodium chloride solution, whereas MEL (CAS number 73-31-4) was dissolved immediately before its use in a mixture of $1 \%$ pure ethanol $(96 \%)$ and $99 \%$ saline.

2.2. Animals. Ten-week-old male Sprague Dawley rats (200$220 \mathrm{~g}$ ) were placed in suitable stainless steel cages (5 rats/cage). The animals were reared under a controlled lab environment (dark-light cycle of 12 hours, temperature of $22 \pm 3^{\circ} \mathrm{C}$, and relative humidity of $50 \pm 10 \%$ ), and food and tap water were provided ad libitum. After one week of adaptation, the rats were randomly selected and allocated into four groups $(n=7)$; the control (CON) group was administered physiological saline containing $1 \%$ ethanol, the $\mathrm{AlCl}_{3}$ group received $34 \mathrm{mg}$ of $\mathrm{AlCl}_{3} / \mathrm{kg}$ bwt $\left(1 / 25 \mathrm{LD}_{50}\right)$ in accordance with the study by Yousef and Salama [12], the MEL group was injected $5 \mathrm{mg}$ of MEL/kg bwt, and the MEL+ $\mathrm{AlCl}_{3}$ group was injected with $5 \mathrm{mg}$ of MEL/kg bwt for 30 minutes before the administration of $\mathrm{AlCl}_{3}$. Doses of MEL and $\mathrm{AlCl}_{3}$ were administered once daily for eight weeks.

This study was reviewed and approved by the Ethical Committee of the University of Ha'il (number 1 on
$25 / 8 / 1440 \mathrm{H})$. It was also conducted in accordance with the European Community Directive (86/609/EEC) and the national rules on animal care, which follow the NIH Guidelines for the Care and Use of Laboratory Animals (8th edition).

2.3. Sample Collection. Twenty-four hours after the last administration, the rats were sacrificed under anesthesia, and then their blood was collected and centrifuged to obtain serum for biochemical assays. The liver and kidney were quickly collected, weighed, cleaned, and then cut into small pieces (100 mg each). One of the pieces from each group was homogenized in cold phosphate buffer $(\mathrm{pH}$ 7.4) and then centrifuged at $4000 \times g$ for 10 minutes at $4^{\circ} \mathrm{C}$. The resulting supernatants were used for biochemical analyses. The remaining pieces of the animals' liver and kidney were frozen at $-80^{\circ} \mathrm{C}$ until they were used for $\mathrm{Al}$ determination and gene and protein expression analyses.

\subsection{Biochemical Analyses}

2.4.1. Al Levels in the Animals' Liver and Kidney Tissues. The Al levels in the hepatic and renal tissues were determined by graphite furnace atomic absorption spectrophotometry (GFAAS; Perkin-Elmer 3100) in accordance with a previous study [13]. Al levels are presented as micrograms per gram of wet tissue.

2.4.2. Liver and Kidney Function Tests. For the hepatic and renal function tests, the levels of alanine aminotransferases (ALT), aspartate aminotransferases (AST), bilirubin, creatinine, and urea in serum were determined using specific commercial kits from BioSystems S.A. (Barcelona, Spain) according to the manufacturer's instructions.

2.4.3. Markers of Oxidative Stress. Reduced glutathione (GSH), lipid peroxidation (LPO), and nitric oxide (NO) levels in liver and kidney homogenates were determined using the methods of Giustarini et al. [14], Schaffazick et al. [15], and Bryan and Grisham [16], respectively.

2.4.4. Activities of Antioxidant Enzymes. The activities of superoxide dismutase (SOD) and catalase (CAT) in hepatic and renal homogenates were determined by the methods described by Sun et al. [17] and Luck [18], respectively. The activities of glutathione reductase (GR) and glutathione peroxidase (GPx) were analyzed by the procedures developed by Factor et al. [19] and Weydert and Cullen [20], respectively.

2.4.5. Nrf2 Gene Expression Level. The expression levels of the $\mathrm{Nrf2}$ gene in hepatic and renal tissues were determined by real-time PCR using an ABI PRISM 7500 machine with SYBR Green PCR Core Reagents (Applied Biosystems, Waltham, MA, USA). The PCR amplification conditions were performed for 10 minutes at $95^{\circ} \mathrm{C}$, followed by 40 cycles of $15 \mathrm{~s}$ at $95^{\circ} \mathrm{C}$, and 1 minute at $60^{\circ} \mathrm{C}$. The $\beta$-actin gene was used as a housekeeping gene for normalization. The results are expressed relative to those of the control group, which were normalized to 1 . The primer pairs used in this process are shown in Table 1. 
TABLE 1: Details of primer sequences analyzed in real-time PCR.

\begin{tabular}{lcc}
\hline Name & Sense $\left(5^{\prime}-3^{\prime}\right)$ & Antisense $\left(5^{\prime}-3^{\prime}\right)$ \\
\hline$\beta$-Actin & GCAGGAGTACGATGAGTCCG & ACGCAGCTCAGTAACAGTCC \\
Nrf2 & TTGTAGATGACCATGAGTCGC & ACTTCCAGGGGCACTGTCTA \\
\hline
\end{tabular}

2.5. Western Blot Analysis. The nuclear protein extraction and western blot analysis were performed following the methods described by Almeer et al. [21]. The utilized antibodies included mouse anti-Nrf2 (sc-28379, 1:500; Santa Cruz Biotechnology, Santa Cruz, CA, USA), mouse antihistone H1 (sc-393358, 1:1500; Santa Cruz Biotechnology), and goat antimouse IgG (sc-2039, 1:5,000; Santa Cruz Biotechnology). Immunoblot analyses of antimouse IgG horseradish peroxidase-conjugated antibodies were performed using an enhanced chemiluminescence detection kit (BioRad, USA). Data were acquired in arbitrary densitometric units using the ImageJ software.

2.6. Assessment of Tissue Proinflammatory Markers. The levels of tumor necrosis factor-alpha (TNF- $\alpha$; Cat \# CSBE11987r) and interleukin-1 beta (IL-1 $\beta$; Cat \# CSBE08055r) in the tissues were measured using rat ELISA kits (CUSABIO Life Sciences, China) according to the manufacturer's instructions.

2.7. Histopathological Studies. Small parts of the hepatic and renal tissues were fixed in $10 \%$ paraformaldehyde, embedded in paraffin blocks, sectioned $(4-5 \mu \mathrm{m})$, and then stained with hematoxylin and eosin for microscopic examination.

2.8. Immunohistochemical Analysis. The immune localization of Bcl-2 was analyzed using the method described by Pedrycz and Czerny [22]. Photographs were captured at 400x magnification using an Eclipse E200-LED microscope (Nikon, Tokyo, Japan).

2.9. Statistical Analyses. Data were expressed as mean \pm standard deviation (SD). One-way analysis of variance (ANOVA) followed by Tukey's post hoc test was applied using SPSS (IBM SPSS Statistics for Windows, Version 20.0, 2011, Armonk, NY) to calculate the differences between groups; $p$ values of $<0.05$ were considered significant.

\section{Results}

3.1. Aluminum Levels in Hepatic and Renal Tissues. As shown in Figure 1, there was a marked $(p<0.05)$ increase in the $\mathrm{Al}$ levels in the hepatic and renal tissues of rats in the $\mathrm{AlCl}_{3}$ group compared with those in the CON group. However, the administration of MEL prior to $\mathrm{AlCl}_{3}$ extensively reduced $(p<0.05)$ the levels of $\mathrm{Al}$ in the hepatic and renal tissues of rats in the $\mathrm{MEL}+\mathrm{AlCl}_{3}$ group compared with those in the $\mathrm{AlCl}_{3}$ group. No significant changes were observed in the levels of $\mathrm{Al}$ in the hepatic and renal tissues among rats in the MEL group.

3.2. Results of Liver and Kidney Function Tests. To explore the effect of MEL on $\mathrm{AlCl}_{3}$-induced hepatic and renal dysfunctions, liver and kidney function markers in the serum of rats were analyzed after the administration of $\mathrm{AlCl}_{3}$ for eight weeks. As shown in Table 2, there were significant $(p<0.05)$ increases in the level of bilirubin and the activities of ALT and AST in the $\mathrm{AlCl}_{3}$ group compared with those in the CON group. Similarly, the serum levels of creatinine and urea were markedly $(p<0.01)$ higher in the $\mathrm{AlCl}_{3}$ group than in the CON group. Pretreatment with MEL significantly $(p<0.05)$ prevented the disturbance in the liver and kidney markers.

3.3. Results of Oxidative Stress Markers and Antioxidant Enzyme Activities. The manifested $\mathrm{AlCl}_{3}$-induced oxidative stress in hepatic and renal tissues was caused by significant $(p<0.05)$ increases in the levels of LPO and NO concurrently with a significant $(p<0.05)$ decrease in GSH contents and inhibition of antioxidant enzyme activities in comparison with the CON group. Pretreatment with MEL alleviated these alterations in LPO and GSH levels and antioxidant enzyme activities as shown in Figures 2 and 3. Moreover, the administration of MEL alone improved the GSH content and antioxidant enzyme activities of the hepatic and renal tissues when compared with the $\mathrm{CON}$ group.

3.4. Nrf2 mRNA Expression. Real-time PCR results revealed that $\mathrm{AlCl}_{3}$ significantly $(p<0.05)$ downregulated the mRNA expression of the Nrf2 gene in the hepatic and renal tissues as compared with the CON group. In contrast, the administration of MEL 30 minutes before $\mathrm{AlCl}_{3}$ led to a significant $(p<0.05)$ upregulation of Nrf2 mRNA expression in the hepatic and renal tissues as compared with the $\mathrm{AlCl}_{3}$ group (Figure 4). The administration of MEL alone improved the Nrf2 mRNA expression in the hepatic and renal tissues as compared with the CON group.

Next, we examined the nuclear protein expression of Nrf2. As shown in Figure 4, $\mathrm{AlCl}_{3}$ significantly decreased the protein expression level of Nrf2. Interestingly, MEL showed a protective effect on the nuclear protein expression level of Nrf2, which was consistent with its mRNA expression patterns. MEL treatment alone significantly increased the expression of Nrf2. Our results demonstrated that MEL increased the protein expression level of $\mathrm{Nrf2}$, particularly under oxidative stress.

3.5. Results of Tissue Proinflammatory Cytokines. Figure 5 shows significant $(p<0.05)$ increases in the level of TNF- $\alpha$ and IL- $1 \beta$ levels in the hepatic and renal tissues of the $\mathrm{AlCl}_{3}$ group as compared with the CON group. Pretreatment with MEL significantly $(p<0.05)$ diminished the increases in the levels of TNF- $\alpha$ and IL- $1 \beta$ as compared with the $\mathrm{AlCl}_{3}$-intoxicated rats. 


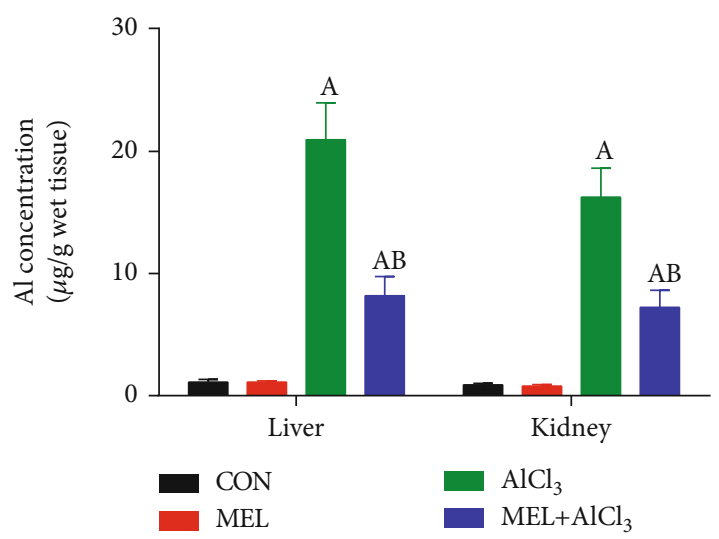

Figure 1: Protective effects of melatonin on the aluminum accumulation in liver and kidney tissues of rats exposed to aluminum chloride $\left(\mathrm{AlCl}_{3}\right)$. Data are expressed as mean $\pm \mathrm{SD}$ values $(n=7) .{ }^{\mathrm{a}} p<0.05$ vs. the control group; ${ }^{\mathrm{b}} p<0.05$ vs. the $\mathrm{AlCl}_{3}$-intoxicated group, using Tukey's post hoc test.

3.6. Results of Histopathological Studies. There were no histological changes detected in the livers of rats in the CON and MEL groups as shown in Figures 6(a) and 6(b), respectively. In contrast, after 8 weeks, the livers of $\mathrm{AlCl}_{3}$-treated rats showed severe hepatic necrosis and disarrangement of hepatic lobules. The portal regions also showed massive granular and vesicular degeneration, inflammatory cell infiltration, and vacuolation (Figure 6(c)). MEL pretreatment largely prevented $\mathrm{AlCl}_{3}$-induced histopathological alterations in the liver, as evidenced by a reduction in the infiltration of inflammatory cells and hepatocytic injuries (Figure 6(d)).

As shown in Figure 7(a), the renal tissues of CON rats had intact renal parenchyma with well-defined glomerular tufts and tubules. $\mathrm{AlCl}_{3}$ intoxication induced degeneration and collapse of the glomeruli of the kidney (Figure 7(c)). Pretreatment with MEL mitigated renal histoarchitecture alteration and resulted in a well-formed glomerulus in Bowman's capsule (Figure 7(d)). Moreover, the administration of MEL alone did not cause any histological abnormalities in the kidneys of rats, as seen in Figure 7(b).

3.7. Results of Immunohistochemical Studies. Immunohistochemical analysis of Bcl-2 revealed minimal immunoreactivity and normal cell life cycles in the hepatic and renal tissues of the CON group (Figures 8(a) and 9(a), respectively). In contrast, the immunostaining activity for Bcl-2 was significantly diminished in the $\mathrm{AlCl}_{3}$ group, which manifested the apoptotic action of $\mathrm{Al}$ in the hepatic and renal tissues (Figures 8(c) and 9(c), respectively). However, the immunostaining level of Bcl-2 increased markedly in the rats pretreated with MEL, suggesting that MEL has antiapoptotic properties (Figures 8(d) and 9(d), respectively). Moreover, the livers and kidneys of rats treated with MEL alone showed a markedly higher level of Bcl-2 immunostaining than those of rats in the CON group (Figures $8(\mathrm{~b})$ and 9(b), respectively).

\section{Discussion}

Exposure to $\mathrm{Al}$ is extensive owing to the long history of use of this heavy metal in medicine, manufacturing, farming, and water treatment. $\mathrm{Al}$ is absorbed by several routes (oral, intranasal, transdermal, and parenteral) [23]. However, little is known about the hepatotoxic and nephrotoxic actions of $\mathrm{Al}$ in animals and humans. The current investigation was designed to determine whether MEL could protect the hepatic and renal tissues from $\mathrm{Al}$-induced toxicity.

Our findings revealed that intoxication of rats with $\mathrm{AlCl}_{3}$ (34 mg/kg bwt) for eight consecutive weeks resulted in its accumulation in the hepatic and renal tissues. These findings align with those of Al Kahtani [24], who demonstrated that $\mathrm{Al}$ accumulates in the liver and kidney tissues of rats exposed to a high dose of Al.

The present study showed that all rats intoxicated with $\mathrm{AlCl}_{3}$ presented a typical pattern of hepatotoxicity, as confirmed by increases in the levels of ALT, AST, and bilirubin in serum, and the elevated serum creatinine and urea levels indicated nephrotoxicity. Abdel Moneim et al. [3] found that the accumulation of $\mathrm{Al}$ in organs results in molecular impairment or dysfunction. Our results agree with those of $\mathrm{Al}$ Kahtani and Morsy [25], who reported that the main symptoms of $\mathrm{Al}$ hepatotoxicity and nephrotoxicity are elevated levels of liver and kidney function markers. As confirmed by Abdel Moneim et al. [3], liver enzymes are important biomarkers of hepatocellular injury. Yousef et al. [5] concluded that exposure to $\mathrm{AlCl}_{3}$ causes liver necrosis, severe destruction to the cellular membranes, and subsequent discharge of intracellular enzymes and bilirubin into the blood circulation. In the present study, $\mathrm{AlCl}_{3}$-induced liver and kidney injuries were confirmed by a histopathological assessment, which revealed many deleterious morphological alterations in the liver and kidney tissues of the $\mathrm{AlCl}_{3}$ group. These observations were consistent with the findings of Yousef et al. [5] and Morsy et al. [26].

The mechanism of Al toxicity is far from being fully understood, although it has been suggested that ROS is the key player in Al-induced hepatorenal toxicity [25]. Increased ROS levels are attributed to mitochondrial hyperactivity, electron leakage, and enhanced electron transport chain activity. Indeed, ROS attacks almost all cellular components, including membrane phospholipids, and causes LPO [27]. As another possible mechanism, Pérez et al. [28] hypothesized that the toxic effects of $\mathrm{Al}$ are mediated by damage to cell membranes. The intracellular increase in ferrous iron levels leads to LPO. Excessive LPO impairs cellular membrane permeability, fluidity, and integrity, which eventually leads to apoptosis.

When free radicals are overproduced, the body defends itself from these radicals by synthesizing enzymatic endogenous antioxidants (such as CAT, SOD, GR, and GPx) or nonenzymatic ones (such as GSH), which represent the first line of defense against free radical damage [29]. In the present study, Al-intoxicated animals demonstrated many markers of oxidative stress as evidenced by increases in the levels of LPO and NO with a simultaneous decrease in the GSH content as well as inhibition in the activities of GPx, SOD, CAT, 
TABLE 2: Protective effects of melatonin on aluminum chloride $\left(\mathrm{AlCl}_{3^{-}}\right)$induced alternation in the liver and kidney markers in serum of rats.

\begin{tabular}{lcccc}
\hline Parameter & CON & MEL & $\mathrm{AlCl}_{3}$ & ${\mathrm{MEL}+\mathrm{AlCl}_{3}}$ \\
\hline ALT (U/l) & $59.31 \pm 3.1$ & $57.56 \pm 4.93$ & $87.65 \pm 8.75^{\mathrm{a}}$ & $61.87 \pm .5 .51^{\mathrm{b}}$ \\
AST (U/l) & $47.78 \pm 2.77$ & $45.76 \pm 3.65$ & $76.54 \pm 6.57^{\mathrm{a}}$ & $55.36 \pm 3.63^{\mathrm{b}}$ \\
Bilirubin (mg\%) & $0.98 \pm 0.05$ & $0.87 \pm 0.07$ & $1.9 \pm 0.75^{\mathrm{a}}$ & $1.1 \pm 0.64^{\mathrm{b}}$ \\
Urea (mg\%) & $43.81 \pm 8.54$ & $45.58 \pm 7.9$ & $76.53 \pm 9.65^{\mathrm{a}}$ & $57.42 \pm 7.58^{\mathrm{ab}}$ \\
Creatinine (mg\%) & $0.55 \pm 0.09$ & $0.61 \pm 0.03$ & $3.2 \pm 0.73^{\mathrm{a}}$ & $1.46 \pm 0.46^{\mathrm{ab}}$ \\
\hline
\end{tabular}

Data are expressed as mean \pm SD values $(n=7) .{ }^{\mathrm{a}} p<0.05$ vs. the control group; ${ }^{\mathrm{b}} p<0.05$ vs. the $\mathrm{AlCl}_{3}$-intoxicated group, using Tukey's post hoc test.
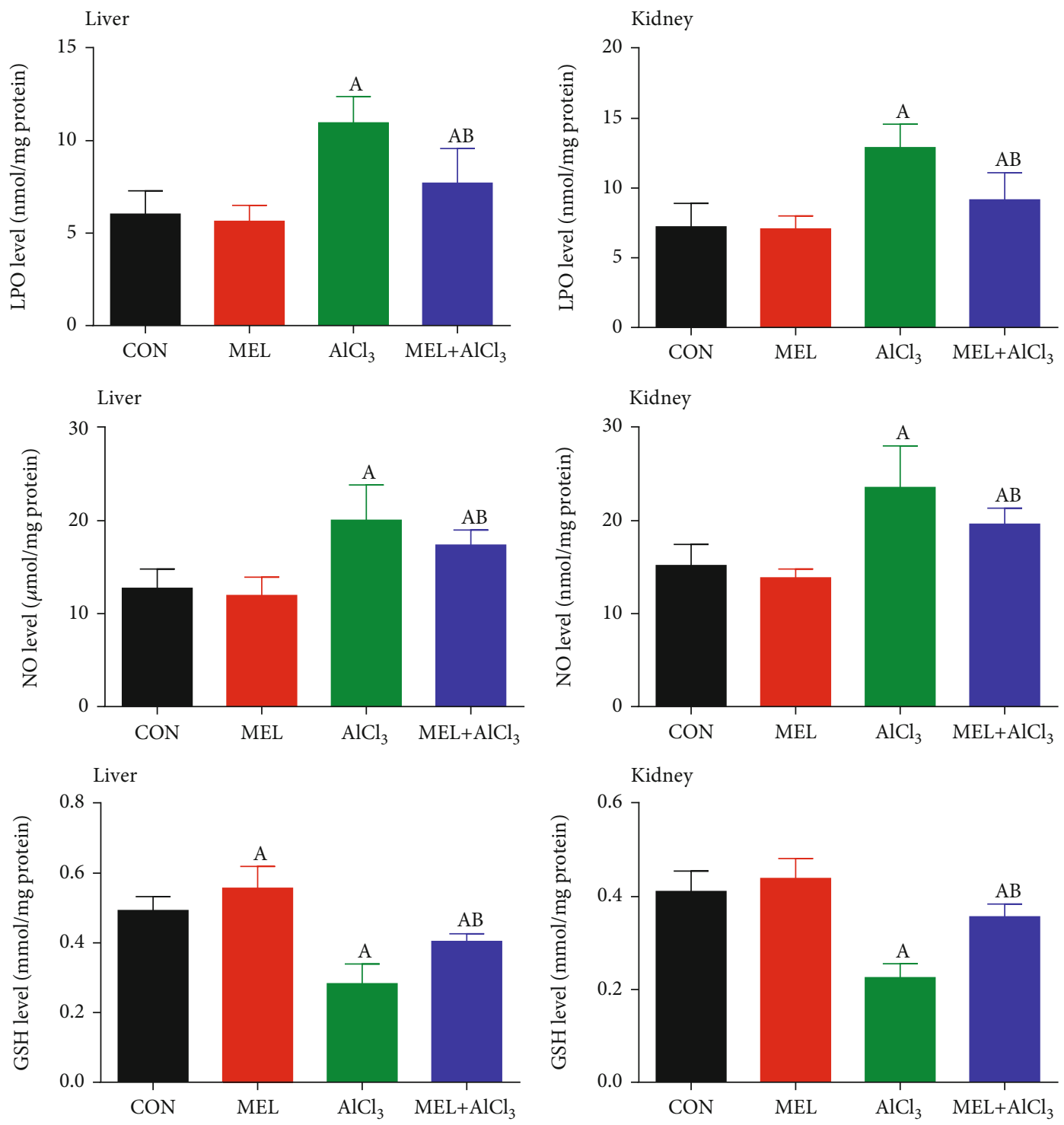

FIGURE 2: Protective effects of melatonin on aluminum chloride $\left(\mathrm{AlCl}_{3^{-}}\right)$induced oxidative stress markers (LPO, NO, and GSH) in the liver and kidney tissues of rats. Data are expressed as mean \pm SD values $(n=7) .{ }^{\mathrm{a}} p<0.05$ vs. the control group; ${ }^{\mathrm{b}} p<0.05$ vs. the $\mathrm{AlCl}_{3}$-intoxicated group, using Tukey's post hoc test.

and GR in the hepatic and renal tissues. This emphasizes the role of free radicals in oxidative cellular damage caused by $\mathrm{Al}$ toxicity. These findings are consistent with those of previous studies, which showed that $\mathrm{Al}$ intake causes oxidative stress and leads to a decrease in the GSH content and the inhibition of antioxidant enzyme activity in different tissues [5, 25]. This inhibition in the activities of antioxidant enzymes observed in this study may be attributed to the reduced biosynthesis of these enzymes owing to higher intracellular levels of $\mathrm{Al}$ and/or the overproduction of free radicals [30]. 

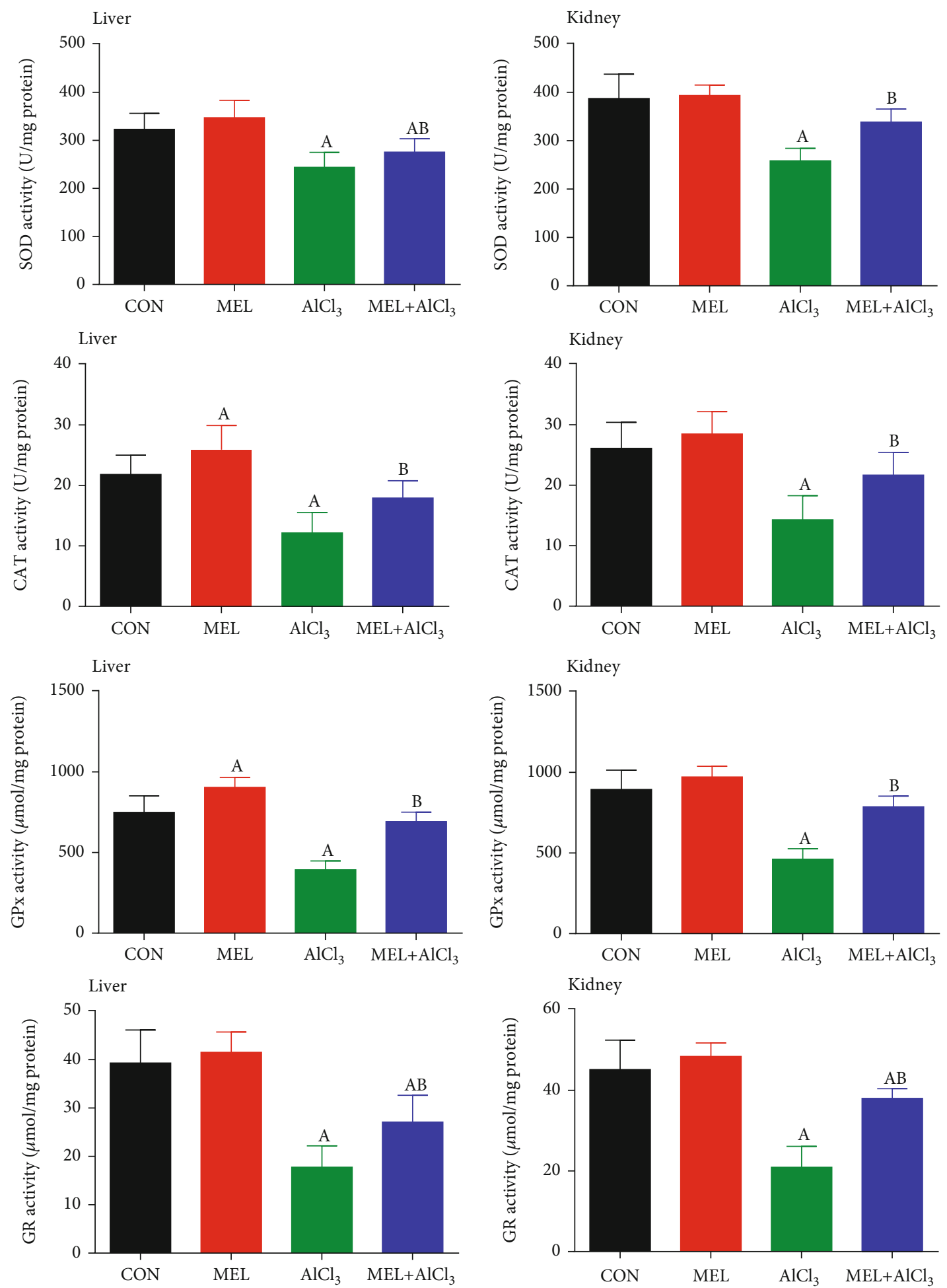

FIgure 3: Protective effects of melatonin on aluminum chloride ( $\left.\mathrm{AlCl}_{3^{-}}\right)$induced inhibition in the antioxidant enzyme activities (SOD, CAT, $\mathrm{GPx}$, and GR) in the liver and kidney tissues of rats. Data are expressed as mean \pm SD values $(n=7) .{ }^{\mathrm{a}} p<0.05$ vs. the control group; ${ }^{\mathrm{b}} p<0.05$ vs. the $\mathrm{AlCl}_{3}$-intoxicated group, using Tukey's post hoc test.

MEL is the most studied molecule with a well-known antioxidant effect. It may offer protection to the body by quenching free radicals and promoting the synthesis of other endogenous antioxidants. In fact, one molecule of MEL can deactivate two hydroxyl radicals. MEL-derived products are believed to augment MEL in protecting against free radicals [31]. Our findings demonstrate that pretreatment of rats with MEL $(5 \mathrm{mg} / \mathrm{kg} /$ day $)$ for eight weeks attenuated $\mathrm{AlCl}_{3}-$ induced hepatic and renal toxicity, as verified by the prevention of $\mathrm{Al}$ accumulation in the liver and kidney tissues. Our 


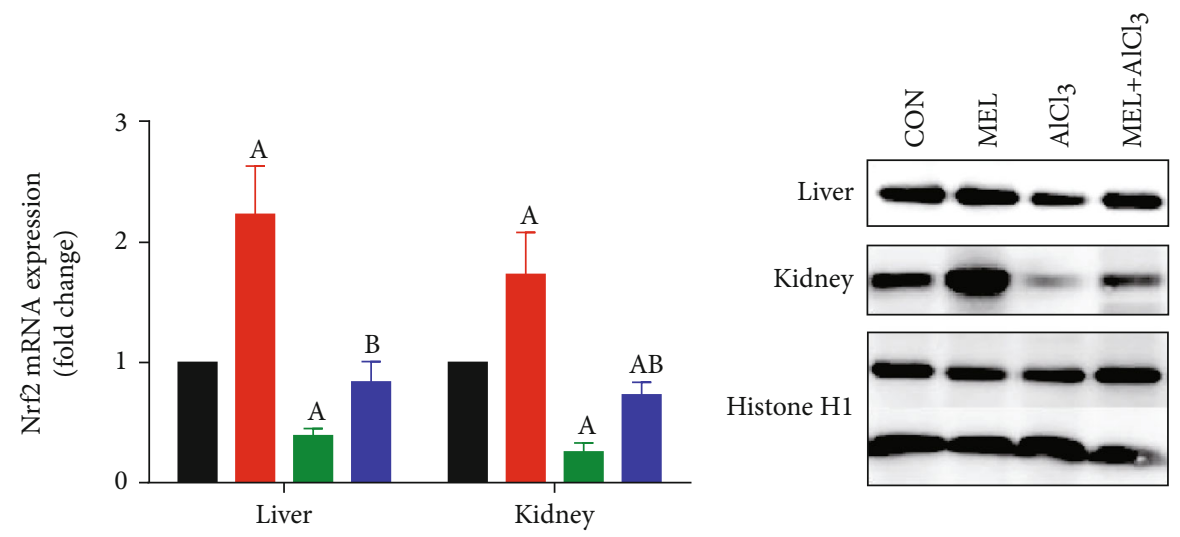

(a)

(b)

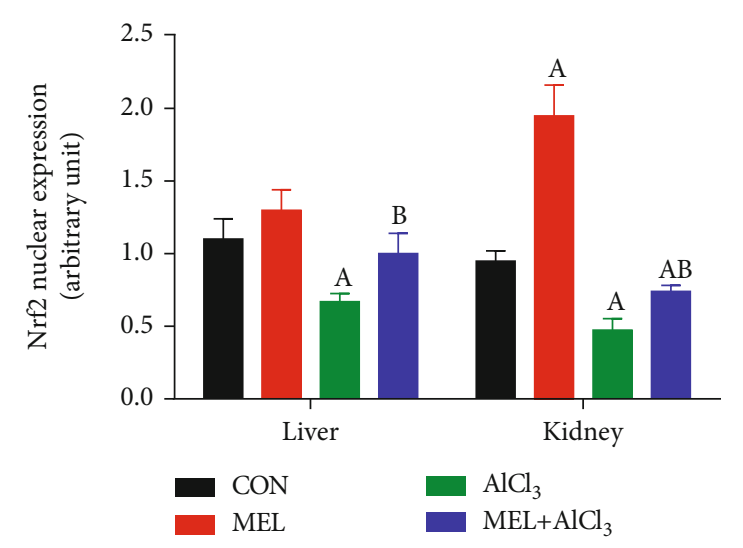

(c)

FIGURE 4: Protective effects of melatonin on aluminum chloride $\left(\mathrm{AlCl}_{3^{-}}\right)$induced downregulation in (a) Nrf2 mRNA expression in the liver and kidney tissues of rats and (b) western blot analysis of Nrf2 protein in the liver and kidney tissues of rats, and (c) quantification of the density of expression level of Nrf2. mRNA data were normalized with $\beta$-actin and represented as fold change (log 2 scale) as compared to mRNA levels from the control rats, and western blot data were normalized with histone $\mathrm{H} 1$ and represented as fold change as compared to protein levels from the control rats. Data are expressed as mean $\pm \mathrm{SD}$ values $(n=5) .{ }^{\mathrm{A}} p<0.05$ vs. the control group; ${ }^{\mathrm{B}} p<0.05$ vs. the $\mathrm{AlCl}_{3}$-intoxicated group, using Tukey's post hoc test.
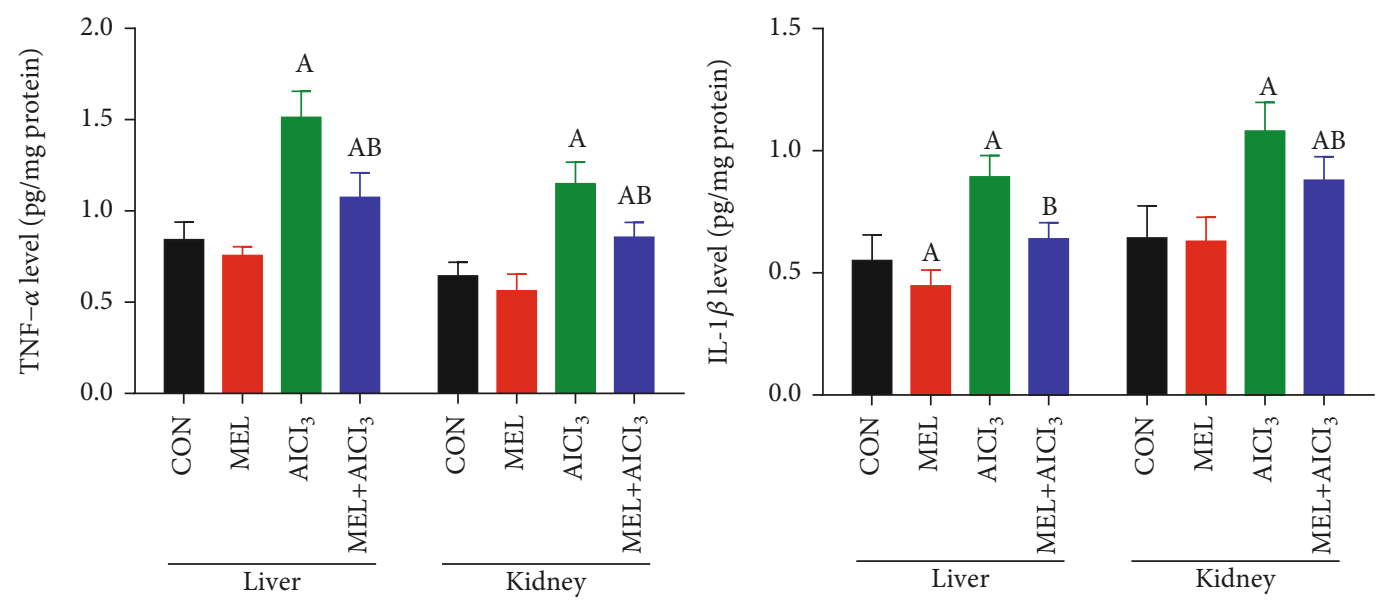

FIGURE 5: Protective effects of melatonin on aluminum chloride $\left(\mathrm{AlCl}_{3^{-}}\right)$induced inflammation in the liver and kidney tissues of rats. Data are expressed as mean \pm SD values $(n=7) .{ }^{\mathrm{a}} p<0.05$ vs. the control group; ${ }^{\mathrm{b}} p<0.05$ vs. the $\mathrm{AlCl}_{3}$-intoxicated group, using Tukey's post hoc test. 


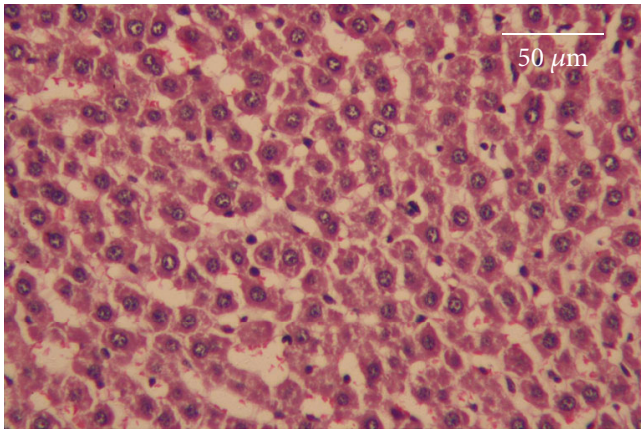

(a)

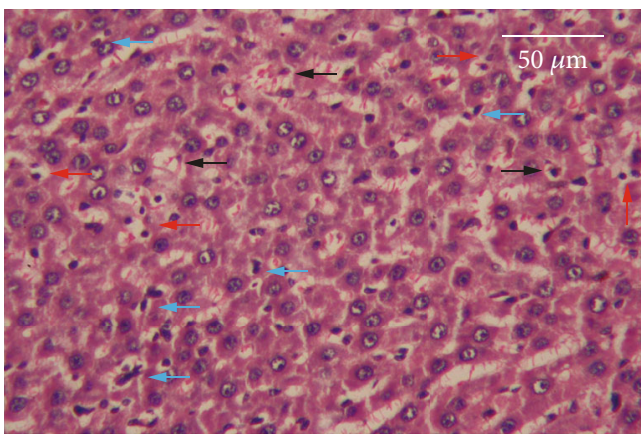

(c)

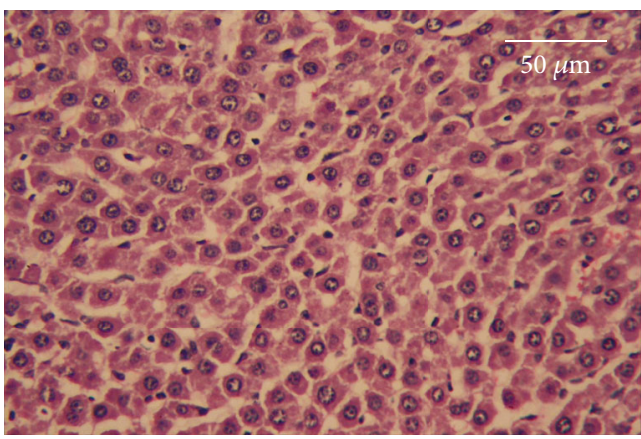

(b)

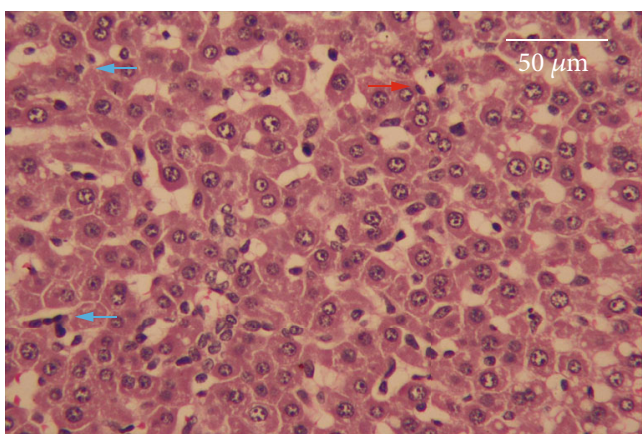

(d)

FIGURE 6: Effects of melatonin on pathological changes in liver tissues of rats exposed to aluminum chloride ( $\mathrm{AlCl}$ ): (a) control, (b) MEL, (c) $\mathrm{AlCl}_{3}$, and (d) $\mathrm{MEL}+\mathrm{AlCl}_{3}$. Magnification at 400x. The red arrow indicated apoptotic hepatocytes, the blue arrow indicates inflammatory cells infiltrated, and the black arrow indicates degenerated hepatocytes.

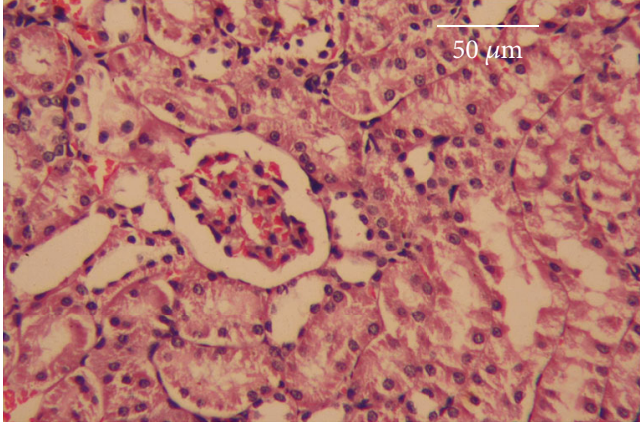

(a)

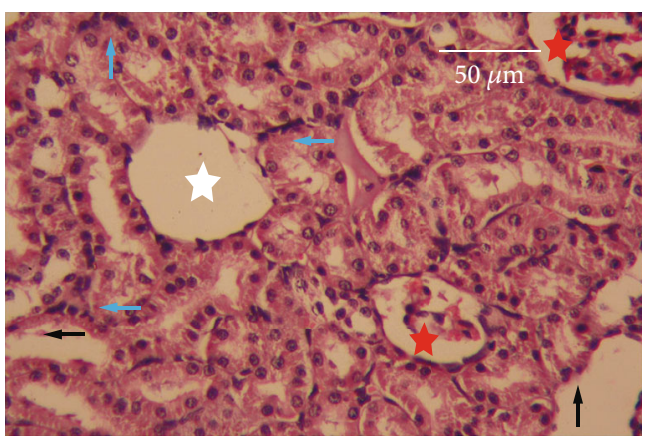

(c)

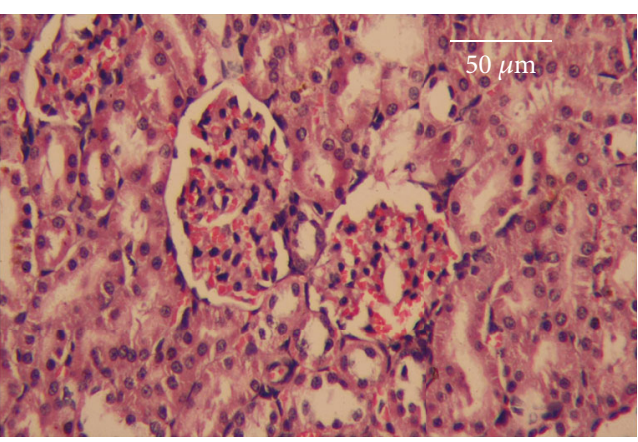

(b)

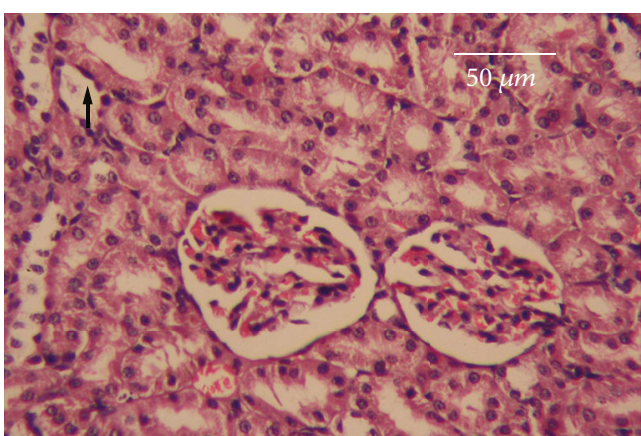

(d)

FIGURE 7: Effects of melatonin on pathological changes in the kidney tissues of rats exposed to aluminum chloride $\left(\mathrm{AlCl}_{3}\right)$ : (a) control, $(\mathrm{b})$ MEL, (c) $\mathrm{AlCl}_{3}$, and (d) $\mathrm{MEL}+\mathrm{AlCl}_{3}$. Magnification at 400x. The red star indicates congested glomerulus, the white star indicates degenerated glomerulus, the blue arrow indicates inflammatory cells infiltrated, and the black arrow indicates degenerated renal tubules. 


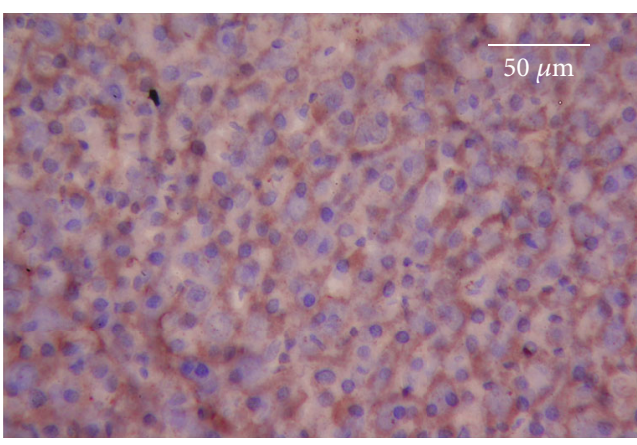

(a)

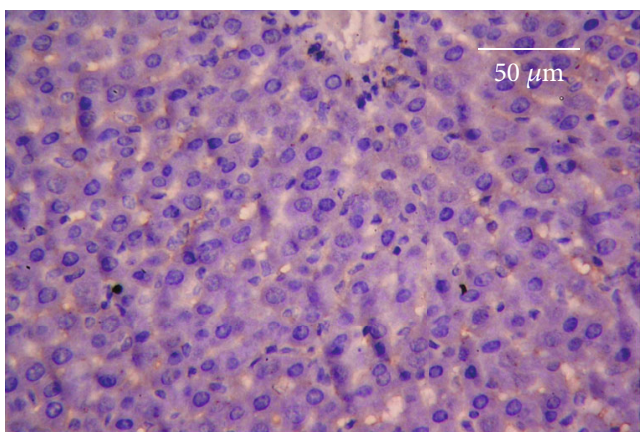

(c)

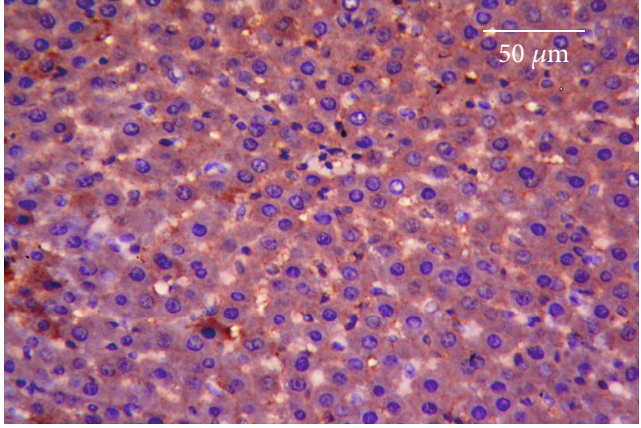

(b)

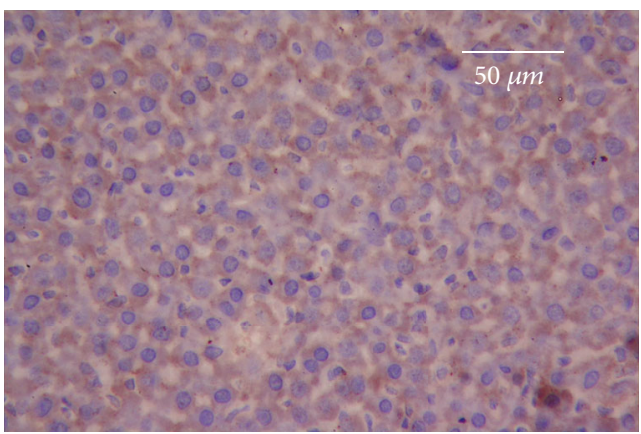

(d)

FIGURE 8: Effects of MEL on Bcl-2 immunostaining of the liver tissues of rats exposed to aluminum chloride ( $\left.\mathrm{AlCl}_{3}\right)$ : (a) control, (b) MEL, (c) $\mathrm{AlCl}_{3}$, and (d) $\mathrm{MEL}+\mathrm{AlCl}_{3}$. Magnification at 400x.

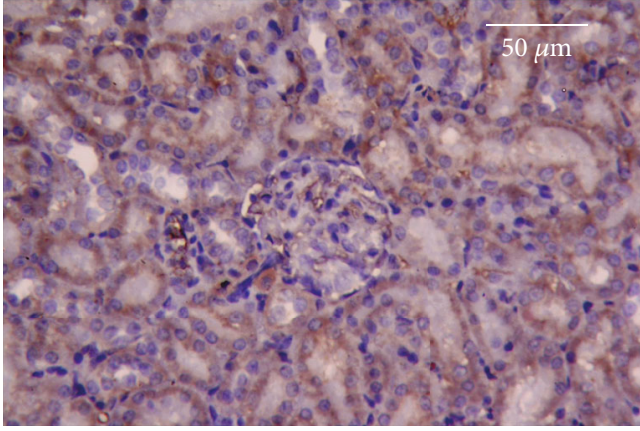

(a)

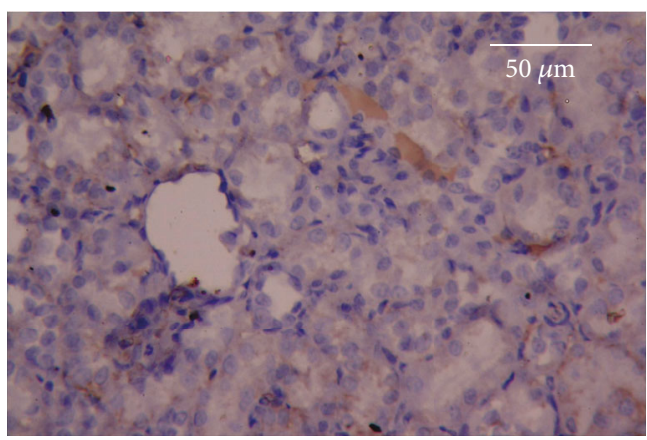

(c)

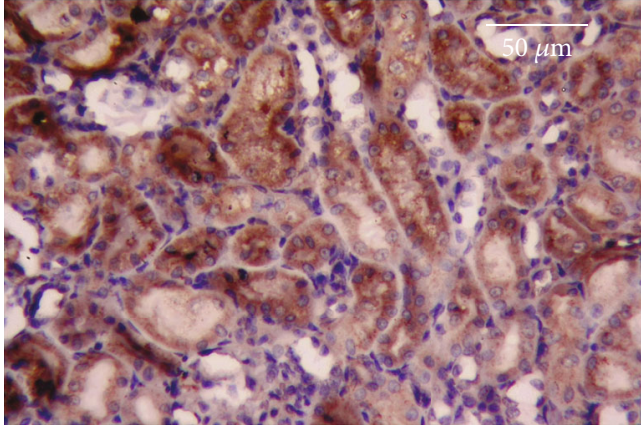

(b)

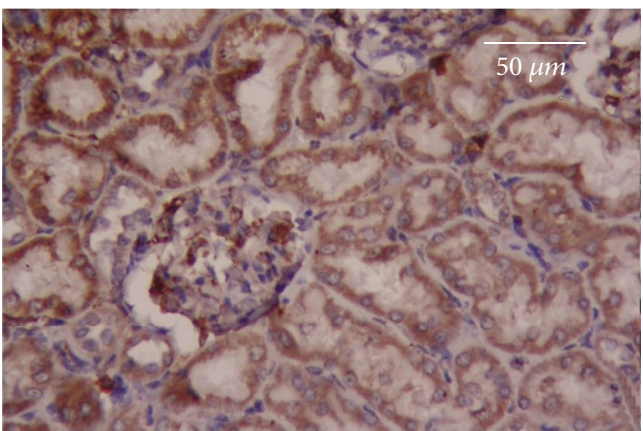

(d)

FIGURE 9: Effects of MEL on the Bcl-2 immunostaining of the kidney tissues of rats exposed to aluminum chloride ( $\left.\mathrm{AlCl}_{3}\right)$ : (a) control, $(\mathrm{b})$ MEL, (c) $\mathrm{AlCl}_{3}$, and (d) MEL+AlCl . Magnification at 400x. 
results are in agreement with those of Romero et al. [32], who postulated that MEL has a chelating effect that may contribute to reducing metal-induced toxicity.

In the present study, pretreatment with MEL considerably inhibited Al-induced liver injury in the rats, as evidenced by reductions in aminotransferase activity and the level of bilirubin. MEL also restored the structures of the hepatic cells and lobules to nearly normal. Furthermore, it significantly decreased the elevation in levels of serum creatinine and urea, leading to a marked improvement in the $\mathrm{Al}$ induced nephrotoxicity and degenerative changes in renal tubules and corpuscles. These findings are in agreement with previous studies, which reported that MEL injection during xenobiotic exposure conferred resistance to the xenobioticinduced unfavorable effects on the hepatic and renal tissues of rats [33-35].

Our results indicate that MEL treatment restored the balance between oxidant and antioxidant molecules, as reflected by the reduction in LPO and NO levels and the increased activity of antioxidant enzymes and GSH content in the liver and kidney tissues. Our results strongly indicated that MEL can alleviate $\mathrm{AlCl}_{3}$-induced oxidative stress by promoting antioxidant enzyme activities and quenching ROS. These findings agree with those of Ko et al. [33] and FernandezGil et al. [36], who demonstrated that MEL not only quenches free radicals but also promotes the activity of antioxidant enzymes, preventing oxidative stress. Tan et al. [37] suggested that the antioxidant effects of MEL result primarily from electron donation and its ability to easily cross morphophysiological barriers. In addition, it can easily reach the different cellular components that enhance the ROS removal effect.

In this study, it was observed that $\mathrm{AlCl}_{3}$ intoxication significantly downregulated the expression level of the Nrf2 gene in the hepatic and renal tissues as compared with the $\mathrm{CON}$ group. These data are in agreement with those of $\mathrm{Yu}$ et al. [38] and $\mathrm{Xu}$ et al. [39], who found that Al toxicity is associated with $N r f 2$ deregulation. One of our most interesting results is that the administration of MEL 30 minutes before $\mathrm{AlCl}_{3}$ upregulated the expression level of the $\mathrm{Nrf2}$ gene in the liver and kidney of rats by more than $100 \%$ as compared with the $\mathrm{AlCl}_{3}$ group. This could suggest that activation of Nrf2 is one of the MEL's key protective mechanisms to relieve $\mathrm{AlCl}_{3}$-induced toxicity. Moreover, the effect of MEL on Nrf2 expression in the liver and kidney of the treated rats aligned with the activities of antioxidant enzymes in this study. Our findings agree with those of Yu et al. [38], who suggested that MEL promotes the mRNA expressions of Nrf2 and its target genes in spleens exposed to $\mathrm{AlCl}_{3}$, suggesting that MEL could facilitate the nuclear translocation of Nrf2, which in turn enhances the spleen's antioxidant capacity.

The observed morphological lesions in the hepatic and renal tissues of $\mathrm{AlCl}_{3}$-intoxicated rats may explain the increased levels of the proinflammatory cytokines TNF- $\alpha$ and IL- $1 \beta$ as compared with the CON group. The data of the present study agree with the results of Zhang et al. [40], Justin-Thenmozhi et al. [41], and Hosny et al. [42], who found that $\mathrm{Al}$ exposure increased the levels of TNF- $\alpha$ and IL- $1 \beta$ in the liver and kidney tissues of rats.
It was previously stated that the pathological bases of $\mathrm{Al}$ toxicity are oxidative stress and apoptosis [43]. Therefore, we explored the effects of MEL on the expression of the Bcl-2 protein, which plays a crucial role in the regulation of apoptotic cell death. Specifically, Bcl-2 inhibits apoptosis in various cell systems and suppresses caspase activity by either preventing cytochrome $\mathrm{C}$ discharges from the mitochondrial matrix and/or binding to the apoptosis-activating factor (APAF-1). Bcl-2 may also attenuate inflammation by impairing the nucleotide-binding domain, leucine-rich repeat protein (NLRP1-) inflammasome activation. Hence, MEL prevents caspase 1 activation and IL- $1 \beta$ release [44]. In this study, $\mathrm{Bcl}-2$ protein expression was markedly downregulated in rats exposed to $\mathrm{AlCl}_{3}$. Thus, $\mathrm{AlCl} 3$ may cause hepatic and renal apoptosis by reducing Bcl-2 expression. Our results are in agreement with those of Li et al. [45].

In the current study, MEL treatment significantly enhanced Bcl-2 expression and thus limited apoptosis and the expression of proinflammatory cytokines such as TNF$\alpha$ and IL- $1 \beta$. Our data suggest that MEL prevented or reversed $\mathrm{AlCl}_{3}$-induced apoptosis and inflammation accompanied by oxidative stress, which may be the basis of MEL's protective role against Al-induced pathological alterations to the liver and kidney tissues of rats. Our findings are consistent with those of Xu et al. [46], who demonstrated that MEL suppresses apoptosis and oxidative stress through a SIRT1dependent mechanism in mouse Leydig cells. Additionally, our findings align with those of Radogna et al. [47], who stated that MEL inhibits apoptosis by regulating apoptosisrelated genes and stabilizing matrix metalloproteinases (MMPs), and those of Dutta et al. [11], who reported that MEL attenuated arsenic-induced nephropathy in mice by preventing oxidative stress and inflammatory signaling cascades.

Based on the results of the current study, we can conclusively state that MEL has the potential to prevent Al-induced hepatotoxicity and nephrotoxicity. This effective role of MEL is related to its free radical scavenging activity, stimulation of Nrf2 and antioxidant enzymes, and inhibition of apoptosis, inflammation, and accumulation of $\mathrm{Al}$ ions. Thus, MEL is of critical importance for the development of novel therapeutic strategies targeting the toxicity associated with chronic $\mathrm{Al}$ exposure.

\section{Data Availability}

All relevant data are within the paper.

\section{Conflicts of Interest}

The authors declare that they have no conflicts of interest.

\section{Acknowledgments}

This research has been funded by the Scientific Research Deanship at the University of Ha'il-Saudi Arabia through project number 160793. 


\section{References}

[1] H. S. Al Dera, "Protective effect of resveratrol against aluminum chloride induced nephrotoxicity in rats," Saudi Medical Journal, vol. 37, no. 4, pp. 369-378, 2016.

[2] E. M. Al-Olayan, M. F. El-Khadragy, and A. E. Abdel Moneim, "The protective properties of melatonin against aluminiuminduced neuronal injury," International Journal of Experimental Pathology, vol. 96, no. 3, pp. 196-202, 2015.

[3] A. E. Abdel Moneim, M. S. Othman, S. M. Mohmoud, and K. M. El-Deib, "Pomegranate peel attenuates aluminuminduced hepatorenal toxicity," Toxicology Mechanisms and Methods, vol. 23, no. 8, pp. 624-633, 2013.

[4] Ö. K. Bulan, B. B. Bayrak, G. Sarikaya-Ünal, and R. Yanardağ, "The influence of melatonin supplementation against aluminum-induced toxicity in brains of male rats," Journal of Research in Pharmacy, vol. 23, no. 2, pp. 275-283, 2019.

[5] M. I. Yousef, T. F. Mutar, and M. A. E. L. N. Kamel, "Hepatorenal toxicity of oral sub-chronic exposure to aluminum oxide and/or zinc oxide nanoparticles in rats," Toxicology Reports, vol. 6, pp. 336-346, 2019.

[6] X. Sun, Z. Cao, Q. Zhang et al., "Aluminum trichloride impairs bone and downregulates $\mathrm{Wnt} / \beta$-catenin signaling pathway in young growing rats," Food and Chemical Toxicology, vol. 86, pp. 154-162, 2015.

[7] P. Lentini, L. Zanoli, A. Granata, S. S. Signorelli, P. Castellino, and R. Dellaquila, "Kidney and heavy metals - the role of environmental exposure (review)," Molecular Medicine Reports, vol. 15, no. 5, pp. 3413-3419, 2017.

[8] X. Wang, J. Gong, Z. Gui, T. Hu, and X. Xu, "Halloysite nanotubes-induced $\mathrm{Al}$ accumulation and oxidative damage in liver of mice after 30-day repeated oral administration," Environmental Toxicology, vol. 33, no. 6, pp. 623-630, 2018.

[9] M. Al-Kahtani, M. M. Abdel-Daim, A. A. Sayed, A. El-Kott, and K. Morsy, "Curcumin phytosome modulates aluminuminduced hepatotoxicity via regulation of antioxidant, Bcl-2, and caspase-3 in rats," Environmental Science and Pollution Research International, vol. 27, no. 17, pp. 21977-21985, 2020.

[10] B. Fernández-Gil, A. E. A. Moneim, F. Ortiz et al., "Melatonin protects rats from radiotherapy-induced small intestine toxicity," PLoS One, vol. 12, no. 4, article e0174474, 2017.

[11] S. Dutta, S. Saha, S. Mahalanobish, P. Sadhukhan, and P. C. Sil, "Melatonin attenuates arsenic induced nephropathy via the regulation of oxidative stress and inflammatory signaling cascades in mice," Food and Chemical Toxicology, vol. 118, pp. 303-316, 2018.

[12] M. I. Yousef and A. F. Salama, "Propolis protection from reproductive toxicity caused by aluminium chloride in male rats," Food and Chemical Toxicology, vol. 47, no. 6, pp. 11681175, 2009.

[13] L. Kubaszewski, A. Ziola-Frankowska, M. Frankowski et al., "Atomic absorption spectrometry analysis of trace elements in degenerated intervertebral disc tissue," Medical Science Monitor, vol. 20, pp. 2157-2164, 2014.

[14] D. Giustarini, P. Fanti, E. Matteucci, and R. Rossi, "Micromethod for the determination of glutathione in human blood," Journal of Chromatography B, vol. 964, pp. 191-194, 2014.

[15] S. R. Schaffazick, A. R. Pohlmann, C. A. S. de Cordova, T. B. Creczynski-Pasa, and S. S. Guterres, "Protective properties of melatonin-loaded nanoparticles against lipid peroxidation," International Journal of Pharmaceutics, vol. 289, no. 1-2, pp. 209-213, 2005.
[16] N. S. Bryan and M. B. Grisham, "Methods to detect nitric oxide and its metabolites in biological samples," Free Radical Biology \& Medicine, vol. 43, no. 5, pp. 645-657, 2007.

[17] Y. Sun, L. W. Oberley, and Y. Li, "A simple method for clinical assay of superoxide dismutase," Clinical Chemistry, vol. 34, no. 3, pp. 497-500, 1988.

[18] H. Luck, "Catalase," in Methods of Enzymatic Analysis, H. U. Bergmeyer, Ed., pp. 855-888, Academic Press, New York, 1965.

[19] V. M. Factor, A. Kiss, J. T. Woitach, P. J. Wirth, and S. S. Thorgeirsson, "Disruption of redox homeostasis in the transforming growth factor- $\alpha / c$-myc transgenic mouse model of accelerated hepatocarcinogenesis," The Journal of Biological Chemistry, vol. 273, no. 25, pp. 15846-15853, 1998.

[20] C. J. Weydert and J. J. Cullen, "Measurement of superoxide dismutase, catalase and glutathione peroxidase in cultured cells and tissue," Nature Protocols, vol. 5, no. 1, pp. 51-66, 2010.

[21] R. S. Almeer, G. I. AlBasher, S. Alarifi, S. Alkahtani, D. Ali, and A. E. Abdel Moneim, "Royal jelly attenuates cadmiuminduced nephrotoxicity in male mice," Scientific Reports, vol. 9, no. 1, article 5825, 2019.

[22] A. Pedrycz and K. Czerny, "Immunohistochemical study of proteins linked to apoptosis in rat fetal kidney cells following prepregnancy adriamycin administration in the mother," Acta Histochemica, vol. 110, no. 6, pp. 519-523, 2008.

[23] C. C. Willhite, N. A. Karyakina, R. A. Yokel et al., "Systematic review of potential health risks posed by pharmaceutical, occupational and consumer exposures to metallic and nanoscale aluminum, aluminum oxides, aluminum hydroxide and its soluble salts," Critical Reviews in Toxicology, vol. 44, Supplement 4, pp. 1-80, 2014.

[24] M. A. Al Kahtani, "Renal damage mediated by oxidative stress in mice treated with aluminium chloride: protective effects of taurine," Journal of Biological Sciences, vol. 10, pp. 584-595, 2010.

[25] M. Al-Kahtani and K. Morsy, "Ameliorative effect of selenium nanoparticles against aluminum chloride-induced hepatorenal toxicity in rats," Environmental Science and Pollution Research, vol. 26, no. 31, pp. 32189-32197, 2019.

[26] G. M. Morsy, K. S. Abou El-Ala, and A. A. Ali, "Studies on fate and toxicity of nanoalumina in male albino rats: oxidative stress in the brain, liver and kidney," Toxicology and Industrial Health, vol. 32, no. 2, pp. 200-214, 2013.

[27] E. M. al Olayan, A. S. Alouf, O. D. AlAmri, O. H. el-Habit, and A. E. Abdel Moneim, "Protocatechuic acid mitigates cadmium-induced neurotoxicity in rats: role of oxidative stress, inflammation and apoptosis," Science of the Total Environment, vol. 723, article 137969, 2020.

[28] G. Pérez, N. Pregi, D. Vittori, C. Di Risio, G. Garbossa, and A. Nesse, "Aluminum exposure affects transferrin-dependent and -independent iron uptake by K562 cells," Biochimica et Biophysica Acta (BBA) - Molecular Cell Research, vol. 1745, no. 1, pp. 124-130, 2005.

[29] O. M. Ighodaro, J. O. Omole, O. A. Ebuehi, and F. N. Salawu, "Aluminium-induced liver and testicular damage: effects of Piliostigma thonningii methanolic leaf extract," Nigerian Quarterly Journal of Hospital Medicine, vol. 22, no. 3, pp. 158-163, 2012.

[30] M. Nampoothiri, J. John, N. Kumar, J. Mudgal, G. K. Nampurath, and M. R. Chamallamudi, "Modulatory role of simvastatin 
against aluminium chloride-induced behavioural and biochemical changes in rats," Behavioural Neurology, vol. 2015, Article ID 210169, 9 pages, 2015.

[31] Q.-H. Han, B. Huang, C.-B. Ding et al., "Effects of melatonin on anti-oxidative systems and photosystem II in coldstressed rice seedlings," Frontiers in Plant Science, vol. 8, p. 785, 2017.

[32] A. Romero, E. Ramos, C. de Los Ríos, J. Egea, J. del Pino, and R. J. Reiter, "A review of metal-catalyzed molecular damage: protection by melatonin," Journal of Pineal Research, vol. 56, no. 4, pp. 343-370, 2014.

[33] J. W. Ko, N. R. Shin, T. Y. Jung et al., "Melatonin attenuates cisplatin-induced acute kidney injury in rats via induction of anti-aging protein, Klotho," Food and Chemical Toxicology, vol. 129, pp. 201-210, 2019.

[34] C. Chojnacki, A. Blonska, and J. Chojnacki, "The effects of melatonin on elevated liver enzymes during statin treatment," BioMed Research International, vol. 2017, Article ID 3204504, 7 pages, 2017.

[35] A. E. Abdel Moneim, F. Ortiz, R. C. Leonardo-Mendonca et al., "Protective effects of melatonin against oxidative damage induced by Egyptian cobra (Naja haje) crude venom in rats," Acta Tropica, vol. 143, pp. 58-65, 2015.

[36] B. I. Fernandez-Gil, A. Guerra-Librero, Y. Q. Shen et al., "Melatonin enhances cisplatin and radiation cytotoxicity in head and neck squamous cell carcinoma by stimulating mitochondrial ROS generation, apoptosis, and autophagy," Oxidative Medicine and Cellular Longevity, vol. 2019, Article ID 7187128, 12 pages, 2019.

[37] D. X. Tan, L. C. Manchester, M. P. Terron, L. J. Flores, and R. J. Reiter, "One molecule, many derivatives: a never-ending interaction of melatonin with reactive oxygen and nitrogen species?," Journal of Pineal Research, vol. 42, no. 1, pp. 2842, 2007.

[38] H. Yu, J. Zhang, Q. Ji et al., "Melatonin alleviates aluminium chloride-induced immunotoxicity by inhibiting oxidative stress and apoptosis associated with the activation of Nrf2 signaling pathway," Ecotoxicology and Environmental Safety, vol. 173, pp. 131-141, 2019.

[39] P. Xu, K. Wang, C. Lu et al., "The protective effect of lavender essential oil and its main component linalool against the cognitive deficits induced by D-galactose and aluminum trichloride in mice," Evidence-based Complementary and Alternative Medicine, vol. 2017, Article ID 7426538, 11 pages, 2017.

[40] H. Zhang, P. Wang, H. Yu et al., "Aluminum trichlorideinduced hippocampal inflammatory lesions are associated with IL- $1 \beta$-activated IL-1 signaling pathway in developing rats," Chemosphere, vol. 203, pp. 170-178, 2018.

[41] A. Justin-Thenmozhi, M. Dhivya Bharathi, R. Kiruthika, T. Manivasagam, A. Borah, and M. M. Essa, "Attenuation of aluminum chloride-induced neuroinflammation and caspase activation through the AKT/GSK-3 $\beta$ pathway by hesperidin in Wistar rats," Neurotoxicity Research, vol. 34, no. 3, pp. 463-476, 2018.

[42] E. N. Hosny, H. G. Sawie, M. E. Elhadidy, and Y. A. Khadrawy, "Evaluation of antioxidant and anti-inflammatory efficacy of caffeine in rat model of neurotoxicity," Nutritional Neuroscience, vol. 22, no. 11, pp. 789-796, 2019.

[43] F. Xu, Y. Liu, H. Zhao et al., "Aluminum chloride caused liver dysfunction and mitochondrial energy metabolism disorder in rat," Journal of Inorganic Biochemistry, vol. 174, pp. 55-62, 2017.
[44] B. Faustin, Y. Chen, D. Zhai et al., "Mechanism of Bcl-2 and Bcl-XL inhibition of NLRP1 inflammasome: loop domaindependent suppression of ATP binding and oligomerization," Proceedings of the National Academy of Sciences of the United States of America, vol. 106, no. 10, pp. 3935-3940, 2009.

[45] M. Li, M. Song, L. M. Ren et al., "AlCl3 induces lymphocyte apoptosis in rats through the mitochondria-caspase dependent pathway," Environmental Toxicology, vol. 31, no. 4, pp. 385394, 2016.

[46] G. Xu, J. Zhao, H. Liu, J. Wang, and W. Lu, "Melatonin inhibits apoptosis and oxidative stress of mouse Leydig cells via a SIRT1-dependent mechanism," Molecules, vol. 24, no. 17, p. 3084, 2019.

[47] F. Radogna, M. C. Albertini, M. De Nicola, M. Diederich, I. Bejarano, and L. Ghibelli, "Melatonin promotes Bax sequestration to mitochondria reducing cell susceptibility to apoptosis via the lipoxygenase metabolite 5-hydroxyeicosatetraenoic acid," Mitochondrion, vol. 21, pp. 113-121, 2015. 